\title{
HABILIDADES DE COMUNICAÇÃO INTERPESSOAL ENTRE CASAIS: CONTRIBUIÇÕES DA TERAPIA COGNITIVO COMPORTAMENTAL
}

\section{ARTIGO ORIGINAL}

PANTOJA, Josicleia da Silva ${ }^{1}$

MARTINS, Maria das Graças Teles ${ }^{2}$

PANTOJA, Josicleia da Silva. MARTINS, Maria das Graças Teles. Habilidades de comunicação interpessoal entre casais: Contribuições da terapia cognitivo comportamental. Revista Científica Multidisciplinar Núcleo do Conhecimento. Ano 05, Ed. 10, Vol. 15, pp. 138-164. Outubro de 2020. ISSN: 2448-0959, Link de acesso: https://www.nucleodoconhecimento.com.br/psicologia/comunicacao-

\section{interpessoal}

\section{RESUMO}

Casais, vez por outra, vivem conflitos conjugais cotidianos, porém, a grande questão está na forma como esses conflitos são resolvidos por eles. Entende-se que a comunicação habilidosa entre casais poderá proporcionar satisfação conjugal e melhor resolução nos problemas que surgem. O objetivo deste estudo foi investigar as habilidades sociais de comunicação na relação conjugal e as contribuições da Terapia Cognitivo Comportamental - TCC. Buscou-se ainda, identificar as formas positivas e deficitárias de comunicação no relacionamento conjugal. A metodologia utilizada foi a pesquisa de campo de caráter quanti-qualitativo e exploratório. Os instrumentos aplicados foram o Inventário de Habilidades Sociais Conjugais - IHSC, em 20 (vinte) pessoas casadas formalmente ou não, integrantes de uma instituição religiosa da cidade de Macapá-AP. Os resultados indicam que as mulheres

\footnotetext{
${ }^{1}$ Bacharel em Psicologia, pós-graduanda em Terapia Cognitivo Comportamental.

2 Orientadora. Mestrado em Saúde Coletiva (UNIFESP), Mestrado em Ciências da Educação (ULHT-Portugal).
} 
apresentam maior déficit em autocontrole proativo e os homens maior dificuldade em conversação assertiva. As considerações finais refletem que: As habilidades sociais, treino de comunicação, assertividade e resolução de problemas são componentes técnicos utilizados pela TCC que podem ajudar na forma de comunicação de casais, para que os mesmos possam adquirir estratégias que amenizem seus conflitos. $O$ terapeuta cognitivo comportamental buscará favorecer ao casal, por meio de técnicas e estratégias cognitivo-comportamentais, as habilidades necessárias para uma comunicação positiva. Poderá proporcionar acordos entre os pares para mudança cognitiva, afetiva e comportamental pois, a intervenção na TCC objetiva o estabelecimento do equilíbrio na relação, reduzindo conflitos e distorções cognitivas que permeiam as relações do casal.

Palavras-chave: Habilidade de comunicação, relação conjugal, terapia cognitivo comportamental.

\section{INTRODUÇÃO}

Este estudo apresenta os resultados de uma pesquisa de campo, de caráter quantiqualitativa e exploratória, na qual se buscou investigar as habilidades sociais de comunicação na relação conjugal $e$ as contribuições da Terapia Cognitivo Comportamental - TCC. Buscou-se ainda, identificar as formas positivas e deficitárias de comunicação no relacionamento conjugal e o desenvolvimento de uma comunicação assertiva e positiva.

Não é novidade que casais, vez por outra, vivem conflitos conjugais cotidianos, porém, a grande questão está na forma como eles resolvem esses conflitos e, o quanto a dificuldade em resolver problemas de relacionamento afeta a relação conjugal. Muitos desses conflitos ocorrem pela dificuldade de comunicação entre os pares, de externarem seus sentimentos, do julgamento, da falta de compreensão do outro e, às vezes, até por medo de se exporem dentro da relação.

De acordo com Mundim (2010), atualmente os casais passam por muitos desafios, tais como estresse, desemprego, doenças físicas e emocionais, filhos, transporte 
precário, falta de tempo. Casais que têm dificuldades de lidar de maneira assertiva com as dificuldades cotidianas e situações específicas, podem vir a ter alguns comportamentos inadequados que conduzem ao desgaste físico e mental, ou seja, que interfiram no afeto, nos sentimentos e nas emoções.

Para Silva e Vandenberghe (2008), a comunicação envolve o processo onde, um fala e o outro ouve, que apesar de ser um fato que ocorre diariamente na vida das pessoas, ao se tratar de casais, adquire elementos particulares. Essas mesmas autoras fazem notar que a inabilidade de comunicação positiva pode gerar, potencializar ou até manter conflitos conjugais.

As motivações pela escolha desta temática ocorreram durante estágios realizados dentro da academia, onde foi possível vivenciar algumas atividades como; escuta psicológica, roda de conversas em instituições escolares com adolescentes que relatavam conflitos familiares com desentendimentos dos pais e a falta de comunicação no lar. Pode-se observar um número significativo de crianças e adolescentes que sofrem com conflitos familiares, com a dificuldade de comunicação intrafamiliar, com a ausência de comunicação entre os pais, afetando diretamente todo contexto familiar. Partindo dessas observações, pensou-se em levantar dados, por meio da pesquisa de campo, sobre como tem sido a comunicação de casais, para confirmar ou não se há deficiência nesse processo comunicacional.

Este estudo se justifica pela relevância do tema em várias áreas do conhecimento como a psicologia, a educação, o social, a saúde mental dentre outras. É relevante para o profissional da psicologia, uma vez que, oportunidades são oferecidas para que se possam desenvolver estratégias de intervenções na clínica e comunidade. Percebe-se que existem várias pesquisas relacionadas a intervenções com casais, no entanto, existem poucas pesquisas no campo da psicologia realizadas na cidade de Macapá pois, ainda se apresenta sensível, necessitando de ampliação de investigações e produção científica voltadas para este público.

Compreende-se que para trabalhar com casais, com ou sem filhos, faz-se necessária a presença da psicologia, e que, em sua atuação, busque atentar para a forma com 
que essas famílias têm resolvido suas questões e, quando não conseguem, verificar quais estratégias positivas para uma comunicação assertiva, empática, afetuosa, compreensiva podem utilizar para resolução de seus problemas. Os autores Bertoni e Bodenmann (2010, apud COSTA; CENCI E MOSMANN, 2016) esclarecem que situações de conflitos na conjugalidade ocorrem em razão do processo de adaptação, sincronia e amadurecimento da relação ao longo do tempo. Explicitam que os conflitos conjugais ocorrem naturalmente e são frutos interacionais de pessoas de desejam construir projetos de vida em conjunto. Para isso, precisam discutir, negociar e chegar a acordos. A comunicação passa a ser um ponto de atenção nesta relação pois, a comunicação assertiva se torna mais eficiente na relação dos casais.

Diante disso, a TCC possui excelentes e diversificadas estratégias de intervenções terapêuticas para diversos transtornos e apresenta-se como uma forma de terapia que contribui eficazmente com terapia de casais. Beck (1995) apontou que muitos problemas vivenciados dentro do casamento poderiam estar relacionados às cognições disfuncionais de ambos os parceiros. Em seus estudos, ratificou o papel negativo dos pensamentos, crenças, expectativas, atribuições, entre outros que podem estar inseridos na qualidade dos relacionamentos conjugais.

A modalidade da terapia cognitivo comportamental Beckiana consiste na análise e modificação dos pensamentos disfuncionais que são determinantes no estado do humor, no afeto e nos comportamentos do casal. Peçanha e Rangé (2008) asseveram que a TCC vem sendo utilizada em variados problemas com intervenções, inclusive nas questões de casais em desalinho.

Dessa maneira, buscou-se questionar: De que forma a terapia cognitivo comportamental contribui para o desenvolvimento das habilidades sociais de comunicação assertiva e positiva no relacionamento do casal? Compreende-se que os conflitos conjugais permeiam o relacionamento conjugal em todas as suas facetas. Existem muitos problemas que podem conduzir o casal à comunicação negativa ou ineficaz, com conflitos e discussões, entre as quais estão dificuldades específicas, como insatisfação na área sexual, filhos pequenos, adolescentes, entre outros que provocam muito estresse e ansiedade. 
Assim sendo, a Terapia de Casal tem eficácia conforme nos explicita Dattilio (2011) quando afirma que dentro do tratamento com a abordagem cognitivo comportamental, é importante o terapeuta educar os casais e as famílias sobre o modelo de tratamento. O mesmo afirma que, dentro da estrutura e princípios colaborativos da abordagem, é necessário que a família e seus membros entendam os princípios e métodos envolvidos nesse processo. As intervenções cognitivo-comportamentais podem ser realizadas individualmente, em grupo, com casal e com filhos.

Os principais objetivos da TCC no tratamento de casais em conflito são a reestruturação de cognições inadequadas e a modificação de padrões de comunicação disfuncionais, além do desenvolvimento de estratégias de solução de problemas cotidianos. Dessa maneira, a abordagem da TCC contribui para que haja um bem-estar familiar, melhorando a comunicação de seus membros, a começar pelos responsáveis pela família, que por vezes é o casal.

\section{PROCEDIMENTOS METODOLÓGICOS}

Para o desenvolvimento deste estudo, a metodologia utilizada foi a pesquisa de campo quanti-qualitativa e exploratória. Com o objetivo de investigar as habilidades sociais de comunicação na relação conjugal e as contribuições da Terapia Cognitivo Comportamental. Buscou-se ainda identificar as formas positivas e deficitárias de comunicação no relacionamento conjugal, e o desenvolvimento de uma comunicação assertiva e positiva. Gil (2017) esclarece que o estudo de campo procura o aprofundamento de uma realidade específica. A pesquisa exploratória visa "proporcionar maior familiaridade com o problema, com vistas a torna-lo explícito, construir hipóteses e aprimorar ideias", envolve levantamento bibliográfico, entrevistas com pessoas experientes no problema pesquisado (GIL, 2017, p. 41). A pesquisa de campo implica na utilização de medidas previamente estabelecidas, cujos resultados são quantificáveis, garantindo o estabelecimento de conclusões seguras e confiáveis (GIL, 2017; CERVO; BERVIAN E SILVA, 2013).

Richardson (1999, p. 70) afirma que "O método quantitativo, como o próprio nome indica, caracteriza-se pelo emprego da quantificação, tanto nas modalidades de coleta 
de informações quanto no tratamento delas por meio de técnicas estatísticas". $\mathrm{Na}$ pesquisa quanti-quali ou quali-quanti são desenvolvidas duas etapas de pesquisa: na primeira é conduzida a fase qualitativa para se conhecer o fenômeno estudado, posteriormente de posse das informações, parte-se para a construção de um questionário fechado e aplica-se no campo nomeado para pesquisa. Seguem-se as etapas da tabulação, realização da análise dos dados com auxílio de instrumentos estatísticos. (RICHARDSON, 1999; GIL, 2017; CERVO; BERVIAN E SILVA, 2013). Este estilo de pesquisa envolve o interesse do pesquisador, interesse ao problema de pesquisa que, muitas vezes depende de abordagem múltipla para investigação.

\subsection{AMOSTRA}

A amostra da pesquisa foi constituída por 20 (vinte) pessoas casadas, formalmente ou não, heterossexuais, com idades entre 22 e 60 anos, que possuíssem um relacionamento conjugal há mais de 2 (dois) anos, ter no mínimo cursado o ensino médio, pertencentes a uma instituição religiosa localizada na cidade de Macapá-AP.

\subsection{PROCEDIMENTOS DE COLETA DE DADOS}

Para a coleta de dados, foi utilizado como instrumento de pesquisa, o Inventário de Habilidades Sociais Conjugais - IHSC de Villa e Del Prette (2012), composto inicialmente por informações referentes a dados sociodemográficos, com a finalidade de identificar e descrever os sujeitos participantes. Posteriormente, o instrumento, que contém 32 (trinta e dois) itens, irão avaliar a frequência com que comportamentos ou sentimentos de habilidades sociais são emitidos dentro do contexto conjugal, onde cada item irá descrever uma situação específica que ocorre dentro do contexto conjugal, e um sentimento ou comportamento frente a essa situação. O participante optará por marcar a frequência que emite tais comportamentos ou sentimentos, sendo de 0 a 2 (zero a dois) onde para cada 10 situações reajo dessa forma no máximo 2 vezes; 3 a 4 (três a quatro) para cada 10 situações reajo dessa forma no máximo 4 vezes; 5 a 6 para cada 10 situações reajo dessa forma no máximo 6 vezes; 7 a 8 (sete a oito) para cada 10 situações reajo dessa forma no máximo 8 vezes e/ou 8 a 10 (oito a dez) para cada 10 situações reajo dessa forma no máximo 10 vezes. 0 
participante não poderia deixar em branco nenhum item do inventário. Foi explicado ao respondente que, se a situação descrita no item nunca tivesse ocorrido, ele deveria imaginar que, caso acontecesse, como ele acredita que reagiria.

A pesquisa obedeceu às seguintes etapas: Definição do tema pelo pesquisador; Levantamento Bibliográfico para organizar o referencial teórico; Leitura do material; Elaboração do Projeto; Entrega e defesa do Projeto; Revisão do Projeto; Revisão bibliográfica; Contato com os participantes da pesquisa para a explicação e assinatura do Termo de Consentimento Livre e Esclarecido (TCLE); Aplicação do Instrumento; Elaboração do artigo científico e defesa do artigo científico.

\subsection{ANÁLISE DOS DADOS}

A análise dos dados sociodemográficos foi realizada através do programa Excel 2016, em que foram realizados agrupamentos de acordo com a similaridade e realizados cálculos de média e frequências. A apuração dos resultados da aplicação do instrumento utilizado para a pesquisa foi realizada de duas formas, a primeira de modo informatizado para 5 (cinco) participantes, onde foram transportados os dados do respondente para a ficha disponilizada online onde se obteve os percentis, bem como a interpretação dos resultados. A segunda forma foi para 15 (quinze) participantes e a apuração foi manual, seguindo de maneira cuidadosa e criteriosa o manual do instrumento.

Este estudo foi analisado e aprovado pela Plataforma Brasil, a qual é responsável pelo sistema oficial de lançamento de pesquisas para análise e monitoramento do sistema CEP/CONEP, conforme o parecer de ㄲo 16296319.3.0000.5021. Portanto, foi utilizado o Termo de Consentimento Livre e Esclarecido (TCLE), para que os entrevistados manifestassem a sua anuência à participação na pesquisa, segundo o que versa a resolução 466/12 do Conselho Nacional de Saúde (CNS). 


\section{REFERENCIAL TEÓRICO}

\subsection{HABILIDADES SOCIAIS DE COMUNICAÇÃO NA RELAÇÃO CONJUGAL}

A comunicação está presente em tudo que o ser humano, desde o nascimento, percorre por toda a vida, sendo fundamental para a manutenção das relações sociais dos indivíduos. Já nas primeiras relações de contato pode-se perceber a forma como a comunicação vai se desenvolvendo e ganhando significados distintos, onde o bebê começa a aprender a se comunicar com o outro de forma única e particular. $\mathrm{O}$ choro, por vezes, ganha significados diferentes, de fome a dores, em que, para cada dor, um choro diferente.

Dentro desse processo de tornar-se social, cada relação interpessoal irá refletir uma parte essencial da vivência humana, e para manutenção de relações, vai depender em grande parte do desenvolvimento de habilidades sociais (HS). Dessa forma, as relações interpessoais são parte integrante da natureza humana e permeiam toda a vida, estando presentes de maneira direta ou indireta nas diversas etapas do nosso desenvolvimento (PORTELLA, 2011).

De uma forma geral, para que uma boa comunicação seja obtida dentro dos relacionamentos interpessoais e que também haja sincronismo nesse processo de comunicação, infere-se que é preciso ter indivíduos habilidosos socialmente. Caballo (2010) assinala que ser socialmente habilidoso é ter um conjunto de comportamentos que são emitidos em um contexto interpessoal, que expressam sentimentos, atitudes, desejos, opiniões ou direitos desse individuo, de forma apropriada à situação, do mesmo modo respeitando esse comportamento nos demais, além de que esses sujeitos habilidosos, geralmente resolvem os problemas imediatos da situação, minimizando a probabilidade de futuros problemas. Desse modo, para que haja manutenção dos relacionamentos mais íntimos, a comunicação verbal é um instrumento de suma importância (FIGUEIREDO, 2005). 
Em concordância, a comunicação não verbal faz parte do dia a dia e não se tem ideia de sua ocorrência, e nem mesmo como acontece, pois, é natural dos indivíduos (SILVA et al., 2000), elucidando essas formas de comunicação ao relacionamento de um casal, de acordo com Rosset (2016), falar o que precisa e, se necessário, falar e sentir que foi compreendido, é a alma do relacionamento conjugal.

Em uma conversação, é necessário haver essa retroalimentação descontínua, porém, frequente, para saber qual resposta, até para que possa se adequar a quem está escutando. Para quem fala, é imprescindível saber se está sendo compreendido, se quem ouvindo está concordando ou não, ou até mesmo se está sendo agradável ou não (CABALLO, 2010).

Portella (2011) apresenta a capacidade empática como terceira habilidade social de comunicação, e segundo Rogers e Rosenberg (1977 apud PORTELLA, 2011), a empatia que está em você penetra o mundo perceptivo do outro, e ao fazer, sente-se à vontade dentro dele. Almeida (2013) diz que a empatia é primordial nas relações, bem como na comunicação. Para Chapman (2013), encorajar o cônjuge exige uma certa empatia, um olhar para o mundo a partir da ótica do cônjuge, descobrindo primeiro o que é importante para seu parceiro, assim sendo, se é capaz de encorajálo. A empatia está relacionada de forma explícita e significativa com todos os pontos da satisfação marital (SARDINHA; FALCONE; FERREIRA, 2009).

Para Dattílio (2011), quando se proporciona ao casal e membros da família a prática dos três tipos de reações, a não assertiva, assertiva e agressiva, de uns com os outros, pode ser proveitoso para ajuda-los a compreender que os benefícios de terem comportamentos assertivos, pode deixar a relação mais saudável.

Desse modo, uma das formas de enriquecer o relacionamento conjugal é melhorando a comunicação, para que o casal construa um relacionamento efetivo e saudável. Lidar com os problemas do cotidiano, nem sempre é tão simples ou fácil. Dessa maneira, buscar adquirir habilidades de lidar com situações conflituosas e normativas de qualquer relacionamento conjugal deveria fazer parte dos objetivos de todo casal. À vista disso, o casal alcança formas mais apropriadas de tomar decisões importantes 
para a relação, em diversas áreas da vida conjugal, bem como as finanças, a relação com os filhos, sobre os cuidados da casa e até mesmo sobre o futuro do relacionamento.

\subsection{FORMAS DE COMUNICAÇÃO POSITIVA E DEFICITÁRIA NO RELACIONAMENTO CONJUGAL}

As habilidades sociais e de comunicação entre os casais são um fator importante para o relacionamento conjugal. A comunicação positiva gera bem-estar na relação, por outro lado, a comunicação negativa ou fragilizada influi na dinâmica do casal e gera conflitos e insatisfações. A comunicação deficitária é um problema comumente encontrado em casais que, na tentativa de resolverem seus conflitos, acabam por agravar ainda mais a situação, ou desencadeiam um novo problema. Desta forma, a falta de habilidade de comunicação se torna particularmente destrutiva, podendo gerar, potencializar ou manter problemas conjugais (SILVA E VANDENBERGHE, 2008).

Casais que ao tentarem resolver seus problemas, acabam usando da comunicação ineficaz, acabam por agravar ainda mais a situação conflituosa ou até podem motivar outras situações problemáticas (SILVA E VANDENBERGHE, 2008).

Para Hanns (2013), a comunicação destrutiva em geral não favorece o convívio matrimonial, mesmo que dependendo da cultura, época e dos hábitos da família, e mesmo que façam parte do dia a dia do casal. De acordo com Chapman (2013), a forma com que se fala é extremamente importante, o autor traz a importância de quando por algum motivo o parceiro comunicar-se com palavras agressivas, nesse momento de fúria, é necessário optar por permanecer gentil, dessa forma deixará de revidar agressivamente para usar palavras brandas.

Neste cenário de comunicação negativa, muitos são os fatores que podem influenciar na inabilidade de passar ou receber uma mensagem eficaz dentro dessa relação, dentre elas a dificuldade em clarificar uma mensagem emitida, que pode estar relacionada a diversos motivos do indivíduo e também do seu parceiro, pois a 
comunicação é uma via de mão dupla, à medida que se emite uma informação, buscase, como objetivo, ser compreendido, e quando a outra parte não dá esse suporte, pode haver falha nesse processo comunicativo.

Há muitas implicações para uma comunicação eficaz, dentre outras coisas, o próprio ambiente onde ocorra a conversa do casal. É necessário que se tenha um local adequado, é fundamental atentar para o tom de voz, bem como a atitude de quem escuta. É preciso estar atento e receptivo à essa comunicação, pois quando não há essa flexibilidade e empatia no escutar, considerando o que o outro tem a dizer, pode vir a se estabelecer um certo bloqueio nesse processo e, consequentemente, conflitos conjugais emergem com veemência.

$\mathrm{Na}$ relação de um casal, a comunicação é incessante e intensa, para tanto é necessário que o casal aprenda a conversar sobre sua forma de comunicação, pois caso contrário, os sentimentos vão sendo guardados e se tornando cada vez mais embutidos e que quando não expressos, geram comunicações não verbais. Nesse contexto, tudo passa a ser comunicado de forma não verbalizada, e consequentemente o distanciamento do casal acontece, passando a ter dificuldade de deixar claro o que sente, quer ou pensa (ROSSET, 2014).

Esta autora apresenta a existência de algumas compulsões comunicacionais que acontecem com a maioria dos casais, e que requerem um tanto de atenção, dentre elas, o hábito de tentar tranquilizar ou dar conselhos quando o parceiro quer somente falar o que está sentindo, o que está passando ou vivendo em determinada situação. A autora remete ao exercício de ouvir, em uma busca de tentar compreender o que outro está falando, buscar ver a situação sob o ponto de vista do outro, onde se torna mais útil do que querer dá soluções ou críticas.

Portanto, a escuta empática pode ser um bom exercício para tal situação, deveras vezes, o parceiro só quer alguém que o compreenda sem julgamentos, que o permita falar livremente, de suas dores, aflições ou até mesmo de um dia ruim ou não produtivo de trabalho. Godinho (2015, p. 16) descreve que: 
A empatia pode também ser alcançada através de uma escuta cuidadosa sobre aquilo que a outra pessoa diz, muitas vezes adquire-se uma compreensão bastante alargada sobre a perspectiva do outro apenas a ouvir aquilo que tem a dizer, sem haver obrigatoriamente a necessidade de se colocar no seu lugar.

Assim sendo, se a pessoa (nesse contexto, o parceiro) for ouvida aberta e atentamente, há a possibilidade de conhecer as experiências desse indivíduo, podendo se contatar mais rapidamente com o seu mundo interno. Para tanto, é disporse a aprender a ver a situação conflituosa do outro, a partir do que é relevante para essa pessoa, é saber escutar ativamente dentro da relação conjugal, é de uma forma ou de outra abrir mão momentaneamente de suas questões pessoais, a fim de ajudar o outro, dar ao outro o que também gostaria de receber.

A princípio, o falar sobre o outro, ao invés de falar de si mesmo, poderá se configurar em outra compulsão. Muitos casais quando têm dificuldade nesse processo de comunicação, acabam por optarem por uma fala mais acusatória, mesmo que inconsciente, lançam mão de apontar no outro ou de expor o comportamento que a seu ver é negativo, com o objetivo de justificar suas frustações, chateações ou sentimentos negativos.

Destarte; Otero e Guerrelhas (2003) são unânimes em explicar que a comunicação envolve um falar e o outro ouvir, e vice-versa. No entanto, quando se trata de casal, essa situação corriqueira na vida das pessoas, apresenta-se com elementos peculiares. A comunicação entre casal possui características e componentes diferentes. Além disso, na interação do casal existem alguns comportamentos desencadeantes de conflitos que Chistensen e Jacobson (2000); Silva e Vandenberghe (2008) denominam de gatilhos. São eles, a crítica, a exigência, o acúmulo de aborrecimentos, mágoas e a rejeição que de alguma forma desencadeiam desavenças que, por sua vez, são interpretadas e absorvidas com sofrimento e desgaste.

As colocações sobre o que a pessoa mesma sente ou pensa são mais viáveis e transmitem a realidade de seus sentimentos. Desse modo, o parceiro saberá o que seu comportamento desencadeia no outro, exemplificando referir a frase: fiquei 
magoada porque você não chegou na hora combinada para irmos ao supermercado, se torna mais útil do que dizer: Você é completamente irresponsável, só pensa e si mesmo e nunca chega na hora, desse modo falar de si e como se sente com tal atitude do companheiro é uma comunicação mais eficaz do que acusações, pois quando se chega com tais procedimentos de culpabilizar o outro, o parceiro, logo agirá defensivamente, e com isso ambos terão dificuldade de se entenderem, conforme assevera Rosset (2014).

Sendo assim, a interrupção durante a fala do outro é outro hábito prejudicial à comunicação do casal, em que o treino de frear o impulso de interromper a fala do parceiro pode levar a pessoa a descobrir ainda mais daquela pessoa com quem se relaciona. Buscar lidar com a ansiedade para falar é ter autocontrole em uma conversa, é apropriar-se de sensibilidade com o outro e permitir que a pessoa se expresse no momento dela.

\subsection{CONTRIBUIÇÕES DA TERAPIA COGNITIVO COMPORTAMENTAL NAS HABILIDADES DE COMUNICAÇÃO POSITIVA CONJUGAL}

A TCC foi desenvolvida no início da década de 60 como a terapia breve, voltada para o presente e para a depressão, orientada a resolver conflitos atuais e a modificação de cognições e comportamentos disfuncionais (BECK, 1964 apud BECK et al., 1997). Seu precursor, Aaron Beck, desenvolveu teorias e métodos para intervenções cognitivas e comportamentais em pessoas com transtornos mentais (WRIGHT; BASCO E THASE, 2008). Beck, ao se dedicar a uma série de experimentos, acabou por obter resultados que o levou à novas explicações para a depressão, identificou cognições negativas, principalmente pensamentos e crenças que eram as características primárias da depressão. Beck desenvolveu ainda um tratamento breve e que tinha como um dos objetivos testar as evidências dos pensamentos dos pacientes depressivos (BECK, 2014).

Diferentes autores explicitam que a TCC se apresenta como a segunda onda de terapias voltadas para o trabalho com casais. Foi antecedida pela terapia comportamental que teve seu surgimento em países que vivenciavam uma 
discrepância significativa nos papéis de gênero e rígida quanto aos papéis do homem e da mulher dentro da família. Após o fim da segunda guerra mundial, como consequência, muitos homens foram retirados do mercado de trabalho, abrindo assim espaço para as mulheres. Essa nova configuração social levou certamente a uma mudança na estrutura conjugal, sendo assim, os parceiros, para viverem como um casal, mais do que antes, agora precisariam de habilidades de comunicação e resolução de problemas no relacionamento conjugal (VANDENBERGHE, 2006).

Em concordância, Peçanha e Rangé (2008) referem que as terapias comportamentais tiveram influências importantes ao desenvolverem técnicas para o tratamento de casais. De acordo com Beck (1995), dentre os pioneiros nos trabalhos de resolução de problemas conjugais, estão Dr. Janis Abrahms, David Burns, Frank Dattilio, Stower Hausner, Susan Joseph, Chris Padesky e Craig Wiese, todos trabalharam com o enfoque cognitivo.

A literatura especializada descreve que a Terapia Cognitivo Comportamental aplicada a casais, foi introduzida há quase 50 anos com Albert Ellis, que trouxe a importância que cognições desempenham nos conflitos conjugais, e que as disfunções no relacionamento do casal acontecem quando começam a guardar crenças irracionais e sem evidências sobre seus parceiros e também sobre o relacionamento, também ao fazerem juízos negativos, quando por algum motivo seus parceiros não condizem com as expectativas irrealistas (ELLIS E HARPER, 1961 apud DATTILIO, 2011).

Pesquisas apontam que a utilização da TCC com casais, com base nos conceitos desenvolvidos por Beck, vem evoluindo com a aplicação de procedimentos e técnicas que envolve a análise dos processos cognitivos, fatores emocionais e comportamentais adaptados para intervenção com casais com problemas de ordem marital, analisando a qualidade da comunicação e habilidades sociais de comunicação assertiva e positiva.

Além disso, a adoção de métodos cognitivo-comportamentais por terapeutas de casais e família deve-se, conforme Knapp (2004), a diversos fatores, entre eles estão: Evidências de pesquisa sobre sua eficácia; sua atratividade para os clientes que 
valorizam a abordagem proativa na resolução de problemas e na construção de habilidades que podem utilizar para enfrentar futuras dificuldades e sua ênfase na relação colaborativa entre terapeutas e cliente.

Entende-se que o terapeuta, baseado no modelo cognitivo, usará diversos recursos dentro do processo terapêutico para buscar formas de possibilitar ao casal modificar pensamentos distorcidos bem como o conjunto de crenças que cada um adquire no decorrer do seu desenvolvimento e que por vezes são disfuncionais e que causam sofrimento psicológico. A Terapia Cognitivo Comportamental remete ao princípio de que a forma como a pessoa pensa sobre uma determinada situação, influenciará diretamente no modo como irá se sentir. Assim, de acordo com suas crenças negativas ou positivas, os seus pensamentos automáticos causarão ou não um sofrimento psicológico.

Pode-se compreender, com base nos estudos realizados por Beck (1995), que os principais objetivos da TCC no tratamento dos casais em conflito abarcam a reestruturação de cognições inadequadas, o manejo das emoções, a modificação de padrões de comunicação disfuncionais e o desenvolvimento de estratégias para solução de problemas cotidianos mais eficazes conforme esclarecem Peçanha e Rangé (2008).

Ressalte-se que os conflitos conjugais permeiam a humanidade há um período de tempo significativo, e também tem sido alvo de estudos por décadas, bem como o crescente aumento de separações de casais, que vem recebendo um olhar diversificado por pesquisadores e estudiosos no tema. Portanto, o objetivo da TCC é de auxiliar o casal a ampliar o conhecimento de si mesmo e a reconhecer as cognições negativas entre cognições, afetos e comportamentos visando melhor forma de relacionamento interpessoal positivo.

Assim sendo, o terapeuta buscará favorecer, através do treino de comunicação e da resolução de problemas adequada, o aumento de interações positivas e consequentemente a redução das negativas e também acordos sobre a mudança de comportamento do parceiro (EPSTEIN, 1998 apud PEÇANHA E RANGÉ, 2008). 
Desse modo, a terapia cognitiva focaliza na forma como os cônjuges se percebem, positiva ou negativamente, ou até mesmo o que deixam de perceber no outro e também no modo que se comunicam, seja ela boa ou ruim ou o que deixam de comunicar (BECK, 1995).

Com relação à assertividade, fator importe na comunicação do casal, o autor Rangé (2008) faz notar que o comportamento de assertividade se torna essencial no contexto conjugal e a comunicação, enquanto expressão de pensamentos, emoções e sentimentos, são habilidades que podem ser aprendidas e fazerem parte do repertório de habilidades do casal, com isso, facilitam o desenvolvimento de autoconhecimento. As intervenções cognitivo-comportamentais, objetivam o restabelecimento do equilíbrio na relação do casal, aumentando áreas satisfatórias e diminuindo as conflituosas, trabalhando distorções cognitivas e as dificuldades de comunicação e solução de problemas (OSORIO E VALLE, 2009). Algumas das técnicas mais utilizadas são os registros de pensamentos automáticos, exercício escrito que possibilita o casal no processo de identificação de pensamentos, sentimentos e comportamentos.

São esses componentes das habilidades de comunicação que a Terapia Cognitivo Comportamental se propõe a trabalhar e na qual se busca, neste trabalho, pesquisar sob a ótica dos casais a serem investigados.

\section{RESULTADOS}

Apresentam-se os resultados obtidos na pesquisa e expressos em Tabelas e Gráficos numerados. Os dados referentes ao perfil sociodemográfico dos participantes da amostra estão expressos na Tabela 01. Quanto à escolaridade, os entrevistados estão dispostos em ensino médio completo (9); ensino superior incompleto (6); e superior completo (5). No que diz respeito ao tempo de casamento de 1 a 10 anos (12); 11 a 20 anos (4); 21 a 30 anos (4). Referindo o número de filhos, 14 (quatorze) participantes têm entre 0 a 2 filhos e 6 (seis) entre 3 a 5 filhos. A idade apresentou-se com média de 30,42 do sexo feminino, com idade mínima de 22 anos e máximo de 44 anos e com um desvio padrão de 8,23 . Os entrevistados do sexo masculino apresentaram idade 
média de 28,5, com idade mínima de 25 anos e máxima de 56 anos e com um desvio padrão de 11,19 .

Tabela 1 - Perfil sociodemográfico da amostra

\begin{tabular}{|c|c|c|c|c|}
\hline Variável & Níveis & $\begin{array}{l}\text { Frequência } \\
\text { Absoluta }\end{array}$ & $\begin{array}{l}\text { Frequência } \\
\text { Relativa (\%) }\end{array}$ & \\
\hline Sexo & $\begin{array}{l}\text { Masculino } \\
\text { Feminino }\end{array}$ & $\begin{array}{l}8 \\
12\end{array}$ & $\begin{array}{l}40 \\
60\end{array}$ & \\
\hline Escolaridade & $\begin{array}{l}\text { Ensino Médio } \\
\text { Completo } \\
\text { Superior } \\
\text { Incompleto } \\
\text { Superior } \\
\text { Completo }\end{array}$ & $\begin{array}{l}9 \\
6 \\
5\end{array}$ & $\begin{array}{l}45 \\
30 \\
25\end{array}$ & \\
\hline $\begin{array}{l}\text { Tempo de } \\
\text { Casamento (anos) }\end{array}$ & $\begin{array}{l}1 \text { a } 10 \\
11 \text { a } 20 \\
21 \text { a } 30\end{array}$ & $\begin{array}{l}12 \\
4 \\
4\end{array}$ & $\begin{array}{l}60 \\
20 \\
20\end{array}$ & \\
\hline Número de Filhos & $\begin{array}{l}0 \text { a } 2 \\
3 \text { a } 5 \\
\text { Média }\end{array}$ & $\begin{array}{l}14 \\
6 \\
\text { Desvio Padrão }\end{array}$ & $\begin{array}{l}70 \\
30 \\
\text { Mínimo }\end{array}$ & Máximo \\
\hline Idade & $\begin{array}{l}\text { Feminino - } \\
30,42 \\
\text { Masculino - 28,5 }\end{array}$ & $\begin{array}{l}8,23 \\
11,19\end{array}$ & $\begin{array}{l}22 \text { anos } \\
25 \text { anos }\end{array}$ & $\begin{array}{l}44 \text { anos } \\
56 \text { anos }\end{array}$ \\
\hline
\end{tabular}

Fonte: Instrumento de coleta (2020) 
No que tangem as questões relacionadas das habilidades sociais conjugais às questões respondidas no inventário IHSC (VILLA E DEL PRETTE, 2012), além dos resultados de cada item (32) e do escore geral, que possibilitam uma avaliação geral do repertório de habilidades sociais conjugais do respondente, ainda produz cinco escores fatoriais decorrente da análise fatorial que são: Expressividade/empatia (F1); Autoafirmação assertiva (F2); Autocontrole reativo (F3); Autocontrole proativo (F4); Conversação assertiva (F5).

Esses fatores são interpretados a partir da relação com o grupo amostral do inventário, em que se consideram escores acima do percentil 25 e a baixo do percentil 75 , interpreta-se que o respondente é possuidor, de uma forma generalizada, de um repertório bastante elaborado de habilidades sociais conjugais em relação à média, considera-se também que percentis abaixo de 25 , pode inferir um déficit no repertório de habilidades sociais e uma possível necessidade de intervenção. Para continuidade é importante compreender o significado de cada um dos fatores avaliados, conforme descritos no Quadro 1 a seguir.

Quadro 1: Descrição dos fatores avaliados no instrumento

\begin{tabular}{|l|l|}
\hline Fator & $\begin{array}{l}\text { Descrição } \\
\text { F1 }\end{array}$ \\
$\begin{array}{l}\text { Expressividade/empatia } \\
\text { sentimentos, desejos e opiniões positivas ao cônjuge, } \\
\text { por exemplo: elogios, agradecimentos, bem-estar, bem } \\
\text { como os comportamentos de intimidades do casal }\end{array}$ \\
$\begin{array}{l}\text { Autoafirmação } \\
\text { assertiva }\end{array}$ & $\begin{array}{l}\text { Refere-se aos comportamentos de expressar } \\
\text { preferências, sentimentos e opiniões de maneira } \\
\text { assertiva em relação ao cônjuge. }\end{array}$ \\
\hline F3 & $\begin{array}{l}\text { Relaciona-se ao comportamento em que o cônjuge } \\
\text { busca se defender diante de situações potencialmente } \\
\text { Autocontrole reativo } \\
\text { estressantes, mantendo o autocontrole e preservando o } \\
\text { relacionamento }\end{array}$ \\
\hline
\end{tabular}


F4

\section{Autocontrole proativo}

F5

Conversação assertiva
Trata da habilidade de autocontrole que podem ser úteis para uma boa comunicação e entendimento entre o casal. Avalia a habilidade do respondente em perceber se o outro está abalado emocionalmente, aguardar a sua vez de falar e fazer-se compreender.

Nesse fator inclui-se pedidos de um cônjuge para o outro com relação a certos comportamentos (cumprimentos de acordos, esclarecimentos) e à habilidade de reagir assertivamente aos comportamentos do outro como por exemplo: discordar ou pedir que outro aguarde sua vez de falar)

Fonte: Instrumento de pesquisa - Habilidades conjugais (2020)

$\mathrm{Na}$ análise fatorial, comparou-se os percentis gerais dos respondentes, primeiramente de uma forma geral, onde foram divididos em: abaixo da média (percentis abaixo de 25); dentro da média (percentis maiores que 25 e menores que 75); acima da média (para percentis maiores que 75). Obteve-se, então, os seguintes resultados para os 20 (vinte) participantes de ambos os sexos: 12 (doze) participantes estão abaixo da média com percentis entre 3 e 20, totalizando $60 \%$; 8 (oito) participantes estão dentro da média com percentis entre 25 e 60 totalizando 40\%. Obteve-se, também, o quantitativo de ambos os sexos, onde, 12 (doze) participantes estão abaixo da média, sendo 4 (quatro) do sexo masculino, que correspondem a 33\% e 8 (oito) são do sexo feminino, que correspondem a $67 \%$ e; dos 8 (oito) respondentes que se encontram dentro da média, 4 (quatro) são do sexo masculino e 4 (quatro) do sexo feminino. Nenhum participante do total da amostra teve percentil geral acima da média, conforme ilustrados na Tabela 2 a seguir.

Tabela 2 - Análise dos percentis gerais

\begin{tabular}{l|l|l|l|} 
Variáveis & Níveis & Frequência Absoluta & Frequência \\
& & Relativa (\%)
\end{tabular}




\begin{tabular}{|l|l|l|l|}
\hline $\mathbf{0 3 - 2 0}$ & Abaixo da média & 60 & \\
\hline $\mathbf{2 5 - 7 5}$ & Dentro da média & 8 & 40 \\
\hline $\mathbf{7 5}+$ & Acima da média & 0 & 0 \\
\hline (Percentis gerais) & & & \\
\hline Sexo & Abaixo da média & 4 & 33 \\
\hline M & Abaixo da média & 8 & 67 \\
\hline F & Dentro da média & 4 & 50 \\
\hline M & Dentro da média & 4 & 50 \\
\hline F & Acima da média & 0 & 0 \\
\hline M & & & \\
\hline F & & & \\
\hline
\end{tabular}

Fonte: Instrumento de coleta (2020)

Obteve-se resultados e interpretações a partir do percentil de cada um dos cinco fatores avaliados pelo instrumento, onde é possível analisar e inferir em qual fator de habilidade social conjugal o participante pode ter um déficit maior e requerer um treino de habilidades. Os totais de quantitativo de participante por fatores, tanto dos que estão dentro da média quanto os que estão abaixo da média, de uma forma geral e de ambos os sexos, ficaram distribuídos da seguinte forma: dos 8 (oito) participantes que estão dentro da média, 03 (três) desses não apresentam déficit em nenhum fator, 04 (quatro) apresentam déficit em somente um fator, e 01 (um) apresenta déficit em dois fatores. Nenhum participante apresenta déficit em três ou mais fatores. Para os 12 (doze) respondentes que estão abaixo da média, 01 (um) não apresenta déficit em nenhum fator, 05 (cinco) apresentam déficit em somente um fator, 04 (quatro) têm déficit em dois fatores, e 02 (dois) têm déficit em três ou mais fatores conforme ilustrados no Gráfico 1. 
Gráfico 1 - Análise fatorial (por percentil geral e fatorial)

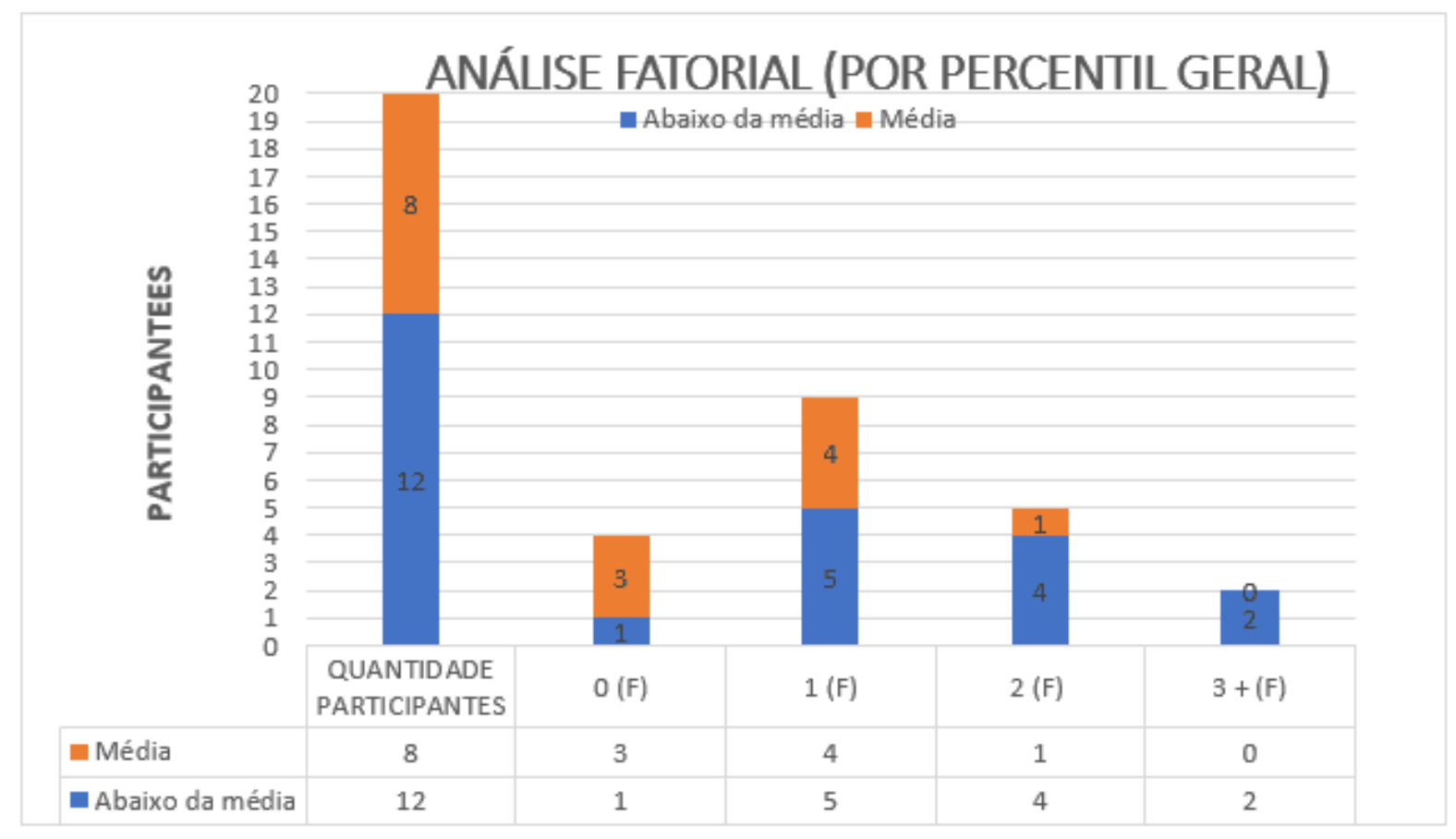

Fonte: Autores da pesquisa

O Gráfico 2 a seguir analisa os percentis do déficit por fator dos 20 (vinte) participantes da pesquisa. Ao se comparar ambos os sexos dos respondentes, obtém-se que, desses, 05 (cinco) pessoas tiveram um percentil abaixo da média no fator Expressividade/empatia (F1) correspondente a 25\% da amostra, sendo 03 (três) do sexo masculino e 02 (dois) do sexo feminino; 20\% da amostra ou 04 (quatro), sendo dois homens e duas mulheres apresentam déficit no fator Autoafirmação assertiva (F2); da amostra total, apenas 02 (duas) pessoas do sexo feminino e nenhum responde do sexo masculino, o que corresponde a 10\%, apresentaram déficit no fator Autocontrole reativo (F3); para o fator Autocontrole proativo (F4) 09 (nove) pessoas apresentaram déficit, equivalente a 45\% da amostra, sendo 07 (sete) mulheres e 02 (dois) homens; e 06 (seis) ou 30\% dos respondentes pode-se inferir déficit no fator Conversação assertiva (F5), sendo que 04 (quatro) são homens e 02 (duas) são mulheres. Conforme Gráfico 2 abaixo. 
Gráfico 2 - Déficit por Fator do total da amostra de ambos os sexos

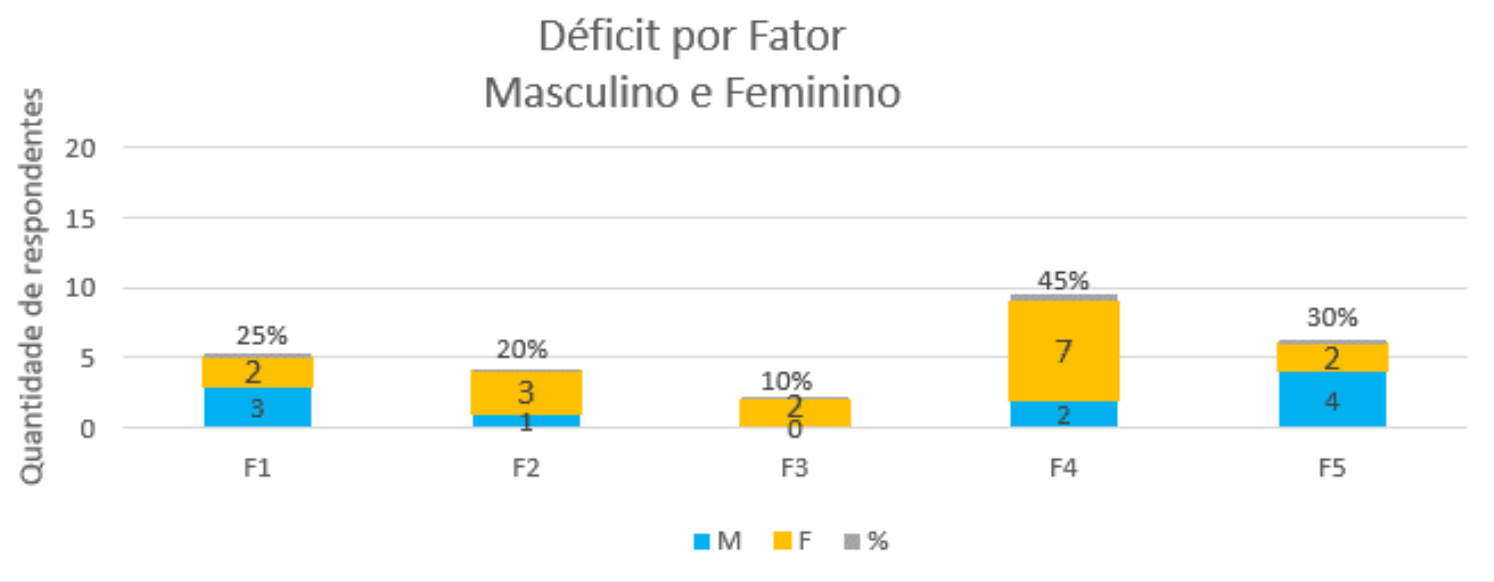

Fonte: Autores da pesquisa

Para a análise dos resultados dos fatores que tiveram maior incidência de respondentes com dificuldades de comportamentos habilidosos, destacam-se os fatores em ordem decrescente de porcentagem e dividimos os respondentes por sexo, que estão destacados na Tabela 3 onde: em destaque está o fator Autocontrole proativo (F4) em que $22 \%$ ou 02 pessoas são homens e $78 \%$ ou 07 (sete) dos respondentes que infere-se um déficit nessas habilidades são mulheres; logo em seguida o fator Conversação assertiva (F5) em que $67 \%$ dos que apresentaram déficit foram 04 (quatro) homens e 33\% ou 02 (duas) pessoas foram mulheres; e o outro com maior incidência foi o fator Expressividade/Empatia (F1), em que 60\% dos respondentes abaixo da média nesse fator são homens (03) e $40 \%$ são mulheres (02)

Tabela 3 - Fatores com maior incidência

\begin{tabular}{|c|c|c|c|}
\hline $\begin{array}{l}\text { Variável } \\
\text { Fatores }\end{array}$ & Níveis & $\begin{array}{l}\text { Frequência } \\
\text { Absoluta }\end{array}$ & $\begin{array}{l}\text { Frequência Relativa } \\
\text { (\%) }\end{array}$ \\
\hline F4 & Masculino & 2 & 22 \\
\hline Autocontrole proativo & Feminino & 7 & 78 \\
\hline
\end{tabular}


F5

Masculino 04

Feminino 02

Masculino 03

F1

Conversação assertiva

Expressividade/Empatia Feminino 02
67

33

60

40

Fonte: Autores da pesquisa - Incidências nas Habilidades Sociais Conjugais (2020)

Cada fator é composto por um grupo de itens do inventário, em que cada participante marca a frequência com que emite o comportamento ou sentimento referido no item em questão. Dos fatores com maior frequência, destacam-se os itens que apresentaram maior frequência de respostas deficitárias dos respondentes, de acordo com a quantidade de participantes que tiveram uma pontuação menor no referido item. Esses dados estão melhor explicitados no Quadro 2 a seguir, onde são apresentados os itens mais recorrentes de cada fator. O nível masculino $(M)$ e feminino $(F)$, e o número (№) de participantes que apresentaram dificuldade no item em questão.

Quadro 2 - Itens com maior frequência de respostas deficitárias

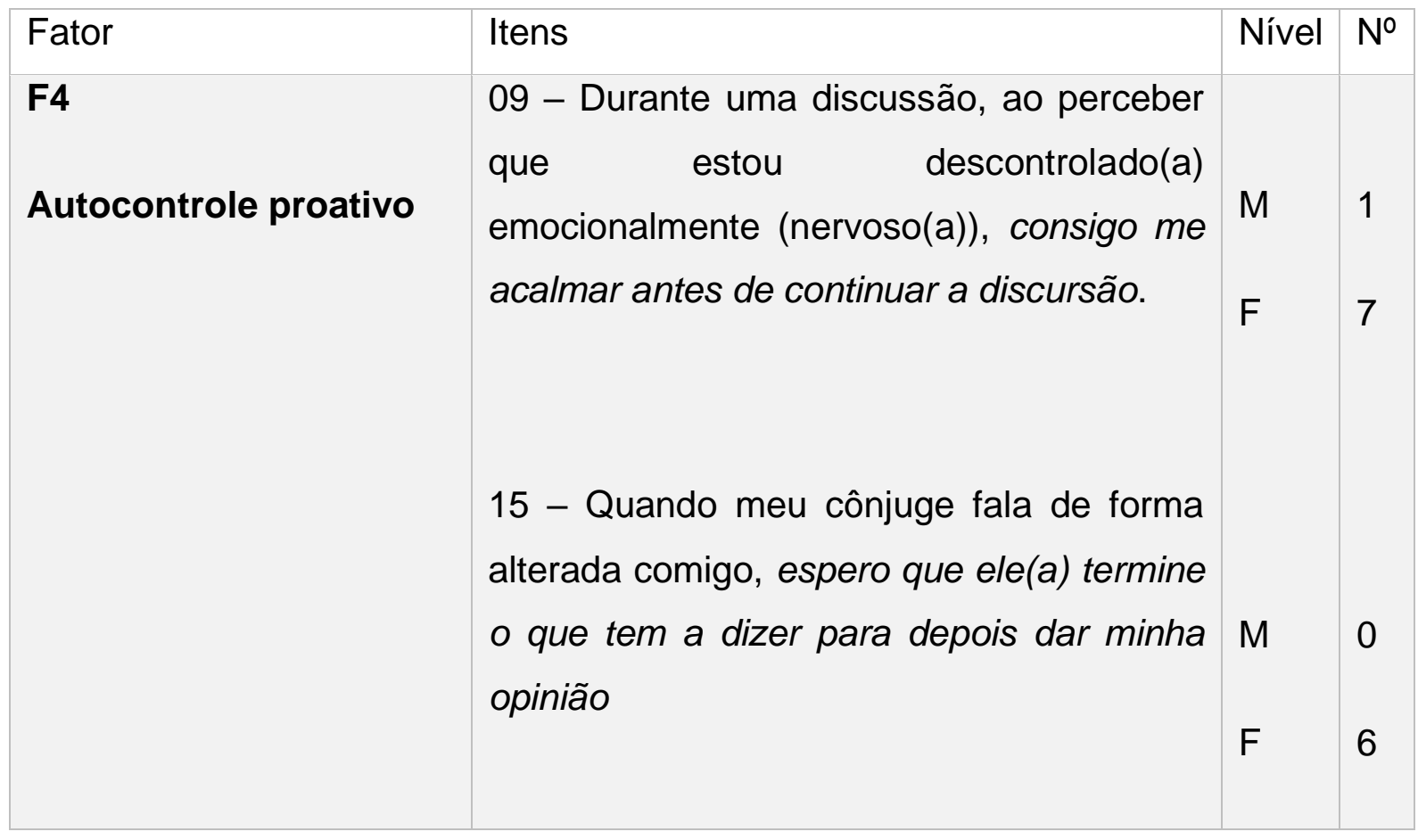




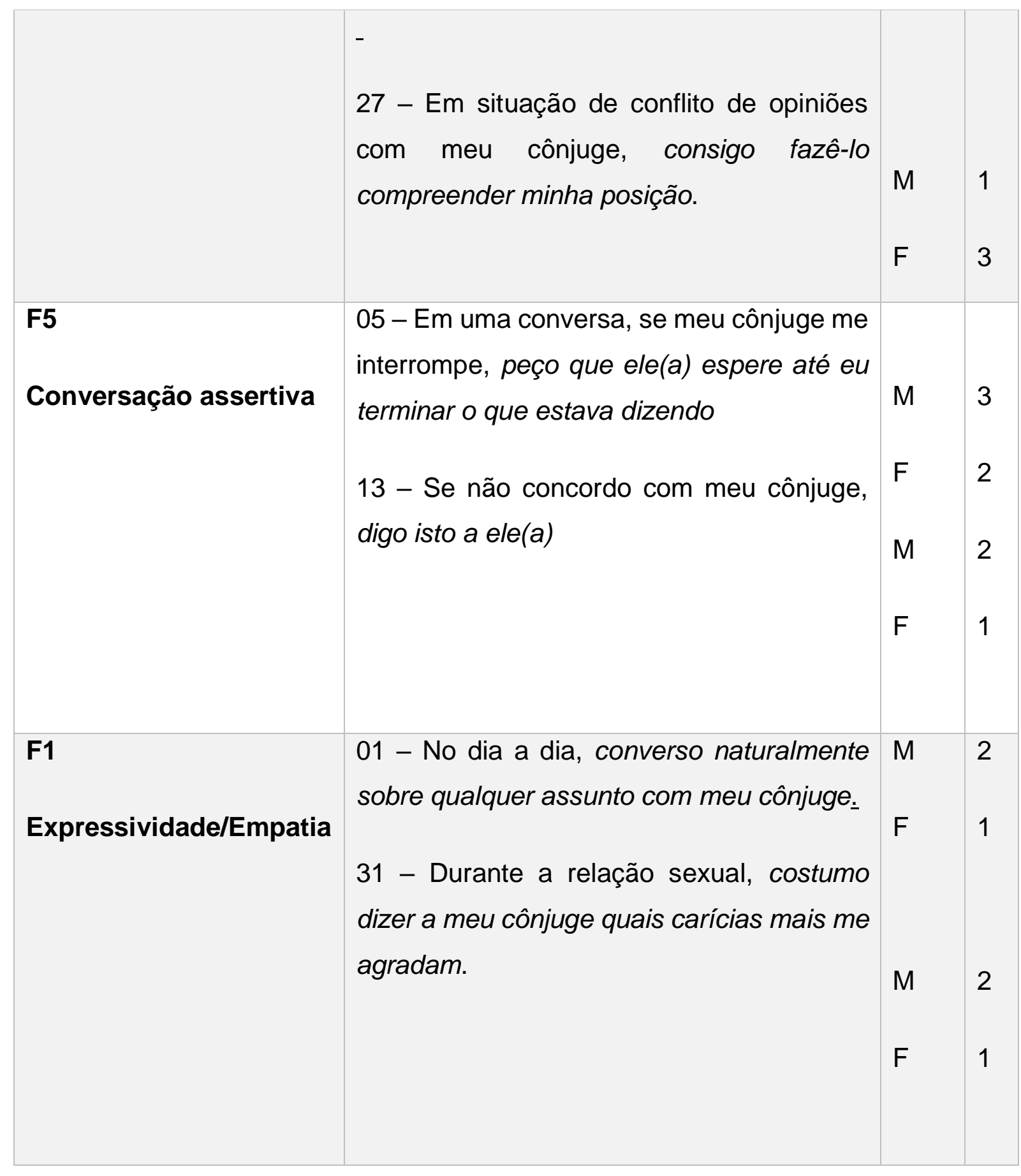

Fonte: Autores da pesquisa - Frequência de comportamento/sentimento deficitário (2020) 


\section{DISCUSSÕES}

Foram obtidos resultados significativos sobre as habilidades sociais conjugais nos participantes, bem como um parâmetro de como se dá a comunicação no contexto conjugal. De forma geral, para que uma boa comunicação seja obtida dentro dos relacionamentos interpessoais e para que haja sincronismo nesse processo de comunicação, é preciso ter indivíduos habilidosos socialmente. Os resultados indicam que as mulheres apresentam maior déficit em autocontrole proativo e os homens maior dificuldade em conversação assertiva.

$\mathrm{Na}$ análise dos percentis gerais explicitados na Tabela 2, que nos dão uma descrição generalizada do repertório de habilidades sociais dentro do contexto conjugal do sujeito, apresentaram-se sujeitos abaixo da média, em que se infere um déficit nessas habilidades, que a partir dos resultados obtidos, conclui-se que $60 \%$ dos participantes encontram-se de alguma forma, com dificuldades nas habilidades que envolvem a comunicação, a expressão emocional, bem como o agir empático. Destaca-se Godinho (2015) quando afirma que a empatia pode ser alcançada por meio de uma escuta cuidadosa sobre aquilo que a outra pessoa diz e, muitas vezes adquire-se uma compreensão ampla sobre a perspectiva do outro.

Esses componentes põem em risco a interação com o cônjuge e o manejo prático do casamento como a resolução de problemas por exemplo. A esse respeito, Caballo (2010) assinala que ser socialmente habilidoso é ter um conjunto de comportamentos que são emitidos em um contexto interpessoal, que expressam sentimentos, atitudes, desejos, opiniões ou direitos desse indivíduo, de forma apropriada à situação, do mesmo modo respeitando esse comportamento nos demais, além de que esses sujeitos habilidosos, geralmente resolvem os problemas imediatos da situação, minimizando a probabilidade de futuros problemas.

Verifica-se que a comunicação deficitária é um problema que foi encontrado nos casais que, muitas vezes na tentativa de resolverem seus conflitos, acabam por agravar ainda mais a situação, ou desencadeiam um novo problema. Assim, a falta de habilidade de comunicação se torna particularmente destrutiva, podendo gerar, 
potencializar ou manter problemas conjugais conforme explicitam Silva e Vandenberghe (2008).

Foi possível perceber que as mulheres apresentaram maior falta dessas aptidões relacionadas aos seus comportamentos sociais, além da dificuldade de emitir esses comportamentos diante de algumas situações e assim obterem um relacionamento desejado. É fato também que nenhum respondente teve resultado acima da média, logo, infere-se que das 20 pessoas participantes, nenhuma possui um repertório, de forma geral, bastante elaborado de habilidades sociais de comunicação. Por outro lado, os $40 \%$ que estão dentro da média apresentam dificuldades em algum fator específico (Gráfico 1).

Destacam-se que as habilidades sociais e de comunicação entre os casais são um fator importante para o relacionamento conjugal. Compreendeu-se que a comunicação positiva gera bem-estar na relação, por outro lado, a comunicação negativa ou fragilizada influi na dinâmica do casal e gera conflitos e insatisfações. Desse modo, casais que ao tentarem resolver seus problemas, acabam usando da comunicação ineficaz e acabam por agravar ainda mais a situação conflituosa ou até podem motivar outras situações problemáticas (SILVA; VANDENBERGHE, 2008).

Sendo assim, é importante considerar que na relação de um casal, a comunicação é incessante e intensa, para tanto é necessário que o casal aprenda a conversar sobre sua forma de comunicação, pois caso contrário, os sentimentos vão sendo guardados e tornando-se cada vez mais embutidos e, quando não expressos, geram comunicações não verbais. Nesse contexto, tudo passa a ser comunicado de forma não verbalizada, e consequentemente, o distanciamento do casal acontece, passando a ter dificuldade de clarificar o que sente, quer ou pensa (ROSSET, 2014).

Dentre os fatores em que mais incorreram baixas médias, tantos de homens quanto de mulheres, está o fator que trata do autocontrole proativo (F4), descrito no Quadro 1 , que envolve aspectos úteis para uma boa comunicação e o entendimento entre o casal. Este fator traz itens relacionados a fazer-se compreender e a percepção do outro, no sentido de perceber a alteração emocional no parceiro e bem como saber 
que é o momento de encerrar uma conversa mais acalorada. Esse comportamento social diz respeito a saber controlar-se diante de sua própria impulsividade sabendo como agir e o momento certo de falar. Para Peçanha (2005), no processo de interação, o casal pode vir a utilizar as palavras de forma inadequada, o que dificultará o processo de assimilação e compreensão do que um dos dois está pensando ou sentindo diante de uma situação específica.

Observam-se que os itens 9 e 15, referidos no Quadro 2, mostram-nos que a incidência é maior nas mulheres e não nos homens, onde elas apresentaram mais dificuldades em fatores de terem o autocontrole diante de uma situação conflituosa. Sendo assim, a interrupção durante a fala do outro, um hábito prejudicial à comunicação do casal em que o treino de frear o impulso de interromper a fala do parceiro, pode levar a pessoa a descobrir ainda mais daquela pessoa com quem se relaciona. Buscando lidar com a ansiedade para falar é ter possibilidade de autocontrole em uma conversa, é apropriar-se de sensibilidade com o outro e permitir que a pessoa se expresse no momento dela.

A título de contribuição, Rosset (2016) refere que muitas brigas são desencadeadas por essas compulsões que aparecem na relação e a maioria desses conflitos são mantidos por elas. Em contrapartida, os homens apresentaram maior dificuldade no fator de conversação assertiva que envolve aspectos referentes ao reagir de forma assertiva diante do comportamento do outro que de certa forma pode ser repulsivo em um dado momento, o que implica em fazer pedidos ao outro que pode causar um certo desagrado (por exemplo, pedir para que o outro aguarde o término de uma fala para que possa assim se pronunciar). A assertividade, está na expressão direta, honesta e adequada de sentimentos, unida a comportamentos equivalentes (PORTELLA, 2011).

Nessa direção, Caballo (2010) esclarece que o comportamento assertivo é capaz de ser aprendido, desse modo, é um processo de aprendizagem, até chegar a ser mais assertivo. Assim, comportar-se assertivamente, é expor de modo direto os próprios sentimentos, necessidades, direitos legítimos ou opiniões, sem ofender, ferir e humilhar o outro, é manifestar quem realmente é como pessoa, com uma mensagem básica e direta: É isso que eu acho! É isso o que eu sinto! Portanto, a assertividade 
implica em declarar suas inquietações e sentimentos sem ira nem passividade de acordo com a posição de Goleman (1995).

Da análise realizada, trazemos em contraponto os fatores que mais se destacaram em termos de respondentes com um repertório de habilidades bem elaboradas, apresentados no Gráfico 2, em que as mulheres apresentam um menor índice no fator 2 (autoafirmação assertiva) referindo aspectos a saber expressar o que prefere, o que sente e como se sente, e sua opinião de modo assertivo em relação ao companheiro.

As colocações sobre o que a pessoa mesma sente ou pensa são mais viáveis, e transmitem a realidade de seus sentimentos, por sequência, o parceiro saberá o que seu comportamento desencadeia no outro, exemplificando referir a frase: fiquei magoada porque você não chegou na hora combinada para irmos ao supermercado, se torna mais útil do que dizer: Você é completamente irresponsável, só pensa e si mesmo e nunca chega na hora. Percebe-se que falar de si e como se sente com tal atitude do companheiro é uma comunicação mais eficaz do que acusações, pois quando se chega com tais procedimentos de culpabilizar o outro, o parceiro, logo agirá defensivamente, e com isso ambos terão dificuldades de se entenderem, conforme assevera Rosset (2014).

Da análise empreendida, verificou-se que o sexo masculino apresentou de forma unânime um repertório bem elaborado de comportamentos socialmente habilidosos no contexto conjugal dentro do fator 3 (autocontrole reativo) apresentado no Quadro 1. Buscam se defender diante de situações potencialmente estressantes, mantendose de forma controlada com o objetivo de preservar o relacionamento. De forma que reagem de maneira mais habilidosa, diante de críticas da parceira, e também o saber lidar com as brincadeiras. Para Del Prette e Del Prette (2008), por mais competente que seja o indivíduo e por melhores que sejam as intenções, é inevitável não se deparar com pessoas que reprovam a forma de pensar e se comportar e expressam isso através da crítica, fazendo-se necessário lidar de forma efetiva com elas.

Apreende-se que a TCC com base nos conceitos desenvolvidos por Beck (1995) desenvolve técnicas de habilidades sociais de comunicação e assertividade que são 
utilizadas no tratamento com casais. Percebe-se que as cognições disfunções, pensamentos ilógicos ou distorcidos, as crenças disfuncionais do conjugue influenciam negativamente no relacionamento, na comunicação e no bem-estar do casal. Esses fatores são fonte geradora de conflitos e desentendimentos.

Portanto, na TCC com casais, busca-se a aplicabilidade de técnicas como reestruturação cognitiva de cognições inadequadas, manejo das emoções, a modificação de padrões de comunicação disfuncionais e desenvolvimento de estratégias para a solução dos problemas enfrentados pelo casal no cotidiano de forma mais coerente e eficaz, conforme nos esclarece Dattilio (2010). Compreendese que todo relacionamento tem seus pontos fortes e frágeis e o terapeuta cognitivo busca reforçar as ações e os pontos positivos dos parceiros para que estes tenham formas assertivas, empáticas e calorosas na interação conjugal.

Por fim, a partir dos dados aqui apresentados, concordamos com a posição dos autores descritos e discutidos na análise da pesquisa realizada, por responder aos objetivos propostos. Foi possível entender que os conflitos, a falta de comunicação e assertividade dos casais ocorre frente a desacordos e pontos de vista diferenciados. No contexto atual, as divergências existentes na comunicação do casal envolvem problemas mais amplos, tais como o tempo que passam juntos, educação dos filhos, tarefas a serem cumpridas e divididas, questões econômicas, sociais, culturais, dentre outras. A partir dos dados apresentados os mesmos despertam interesse e atenção às características individuais, personalidade, temperamento, autoestima, comunicação empática que influenciam a comunicação positiva e negativa do casal.

\section{CONSIDERAÇÕES FINAIS}

O presente trabalho buscou, por meio de um estudo de campo, quanti-qualitativo e exploratório investigar as habilidades sociais de comunicação na relação conjugal e as contribuições da Terapia Cognitivo Comportamental. Buscou-se ainda, identificar as formas positivas e deficitárias de comunicação no relacionamento conjugal, e o desenvolvimento de uma comunicação assertiva e positiva. 
Os resultados do estudo sobre as habilidades sociais conjugais dos participantes foram significativos. A análise dos percentis gerais explicitados nos fornece uma descrição generalizada do repertório de habilidades sociais dentro do contexto conjugal do sujeito. Estes se apresentaram abaixo da média, com déficit nessas habilidades. Concluiu-se que $60 \%$ dos participantes encontram dificuldades nas habilidades que envolvem a comunicação, a expressão emocional, bem como o agir empático.

Os resultados indicam que as mulheres apresentam maior déficit em autocontrole proativo e os homens maior dificuldade em conversação assertiva. As mulheres referem maior déficit dessas aptidões relacionadas aos seus comportamentos sociais, além da dificuldade de emitir esses comportamentos diante de algumas situações e assim obterem um relacionamento desejado. $O$ estudo remete que é fato que nenhum respondente teve resultado acima da média, logo, infere-se que dos 20 (vinte) participantes, nenhum possui um repertório, de forma geral, bastante elaborado de habilidades sociais de comunicação. Por outro lado, os que estão dentro da média, que são 40\%, apresentam dificuldades em algum fator específico (Gráfico 1).

Destaca-se a contribuição de Otero e Guerrelhas (2003), na qual são unânimes em explicar que a comunicação envolve um falar e o outro ouvir, e vice-versa. No entanto, quando se trata de casal, essa situação corriqueira na vida das pessoas se apresenta com elementos peculiares. Além disso, na interação do casal existem alguns comportamentos desencadeantes de conflitos em que diferentes autores, entre eles, Chistensen e Jacobson (2000); Silva e Vandenberghe (2008) denominam de gatilhos que se apresentam com a crítica, a exigência, o acúmulo de aborrecimentos, mágoas e a rejeição que de alguma forma desencadeiam desavenças que, por sua vez, são interpretadas e absorvidas com sofrimento e desgaste.

Com relação as contribuições da TCC, o terapeuta cognitivo comportamental, buscará favorecer, através do treino de comunicação e da adequada resolução de problemas, o aumento de interações positivas e, consequentemente, a redução das negativas e também acordos sobre a mudança de comportamento do parceiro (EPSTEIN, 1998 apud PEÇANHA E RANGÉ, 2008). 
A terapia cognitiva focaliza na forma como os cônjuges se percebem, positiva ou negativamente, ou até mesmo o que deixam de perceber no outro e também no modo que se comunicam, seja ela boa ou ruim ou o que deixam de comunicar (BECK, 1995). As intervenções cognitivo-comportamentais, objetivam o restabelecimento do equilíbrio na relação do casal, aumentando áreas satisfatórias e diminuindo as conflituosas, trabalhando distorções cognitivas e as dificuldades de comunicação e solução de problemas (OSORIO E VALLE, 2009).

A aplicação da TCC no tratamento com casais é eficaz com o uso de técnicas cognitivas e comportamentais entre elas, a restruturação de cognições distorcidas frente a algumas situações do contexto conjugal com déficit de comunicação. $O$ objetivo é proporcionar ao casal habilidades que possam reduzir seus conflitos. $\mathrm{O}$ casal ou parceiro é conduzido a aprender, identificar, avaliar e a responder aos pensamentos distorcidos que influenciam de forma negativa no relacionamento. As técnicas como registro de pensamentos automáticos, flecha descendente, questionamento socrático, diários, recordações, treino na assertividade, dramatizações, dentre outras, são úteis e eficazes.

No tratamento de casais ou parceiro, a parte comportamental é relevante com destaque para as habilidades de comunicação realizadas por meio do treino de comunicação. O objetivo é fornecer ao casal habilidades de escuta e fala que podem reduzir conflitos e aumentar a satisfação e ajustamento conjugal conforme apontam Rangé e Dattilio (2001).

\section{REFERÊNCIAS}

ALMEIDA, Thiago (org.). Relacionamentos amorosos: 0 antes, o durante e o depois deles. São Carlos: Compacta Gráfica, 2013. Disponível em $<$ https://www.academia.edu/5773439/Livro_Completo_Relacionamentos_amorosos_ o_antes_o_durante..._e_o_depois_Volume_1 >. Acesso em: 09 mai 2019.

BECK, A. T.; RUSH, A. J.; SHAW, B. F. \& EMERY, G. Terapia cognitiva da depressão. Porto Alegre: Artes Médicas, 1997. 
BECK, A. T. Para além do Amor. Editora Rosa dos Tempos, 1995. Disponível em $<$ https://pt.scribd.com/doc/123554870/Para-Alem-Do-Amor-Beck>. Acesso em: 04 jun 2019.

BECK, Judith S. Terapia Cognitivo Comportamental: Teoria e Prática. Porto Alegre: Artmed, 2014.

BERTONI, Anna; BODENMANN, Guy. Satisfied and dissatisfied couples: Positive and negative dimensions, conflict styles, and relationships with family of origin. European Psychologist, 15(3),175-184. 2010. IN: COSTA, C. B. da; CENCI, C. M. B.; MOSMANN, C. P. Conflito Conjugal e estratégias de resolução: uma revisão sistemática da literatura. Temas psicol., Ribeirão Preto , v. 24, n. 1, p. 325338, mar. $2016 . \quad$ Disponível em <http://pepsic.bvsalud.org/scielo.php?script=sci_arttext\&pid=S1413389X2016000100017\&lng=pt\&nrm=iso>.

CABALLO, Vicente E. Manual de avaliação e treinamento das habilidades sociais. São Paulo: Santos, 2010. Disponível em $<$ https://www.academia.edu/9553664/Manual_de_Avaliacao_e_Treinamento_das_H abilidades_Sociais> Acesso em: 5 jun 2019

CABALLO, Vicente E. Manual de Técnicas e de Terapias e Modificação do comportamento. São Paulo: Santos, 2003.

CERVO, Amado Luiz; BERVIAN, Pedro Alcino; SILVA, Roberto da. Metodologia científica. 6. ed. São Paulo: Pearson Prentice Hall, 2007.

CHAPMAN, Gary. As 5 linguagens do amor. 3 ed. São Paulo: Mundo Cristão, 2013 CHRISTENSEN, A. \& JACOBSON, N. S. Reconcilable Differences. New York: The Guilford. IN, 2000.

DATTILIO, Frank M. Manual de terapia cognitivo-comportamental para casais e famílias. Porto Alegre: Artmed, 2011. Disponível em 
<https://drive.google.com/drive/folders/OB4cIMwhxlufXaWI0QkVFZ2FaVEU>. Acesso em: 10 maio 2019

DEL PRETTE, Z. A. P.; DEL PRETTE, A. psicologia das habilidades sociais: terapia, educação e trabalho. 5.ed. Petrópolis: Vozes, 2008.

DEL PRETTE, Zilda Aparecida Pereira; VILLA, Miriam Bratfisch; FREITAS, Maura Glória de Freitas; DEL PRETTE, Almir. Estabilidade temporal do Inventário de Habilidades Sociais Conjugais (IHSC). Aval. psicol. [online]. 2008, vol.7, n.1, pp. 6774. ISSN 1677-0471.

Disponível em: http://pepsic.bvsalud.org/scielo.php?script=sci_arttext\&pid=S167704712008000100009 Acesso em: 05 jun 2019

FIGUEIREDO, Patrícia da M. V. A influência de locus de controle conjugal, das habilidades sociais conjugais e da comunicação conjugal na satisfação com o casamento. Rio de Janeiro: Ciência e Cognição, 2005. Disponível em <http://pepsic.bvsalud.org/scielo.php?script=sci_arttext\&pid=S1806$58212005000300014>$ Acesso em: 05 jun 2019

GIL, Antonio Carlos. Como elaborar projetos de pesquisa. 6.ed. São Paulo: Atlas, 2017.

GODINHO, Tânia João Lopes Carriço Gomes. Contributos para a compreensão do processo de empatia e do seu desenvolvimento. Tese de doutorado, Universidade de Évora - Instituto de Investigação e Formação Avançada, 2015. Disponível em $<$ https://dspace.uevora.pt/rdpc/bitstream/10174/14535/11/Doutoramento\%20\%20T\%C3\%A2nia\%20Godinho.pdf> Acesso em: 07 jun 2019.

GOLEMAN, Daniel. Inteligência Emocional. Rio de Janeiro: Objetiva, 1995. Disponível em <https://drive.google.com/file/d/1NPm0p1RzqTHN8vT_VXaxyn05fhF0uHQC/view> Acesso em: 20 mai 2019. 
HANNS, Luiz. A equação do casamento. Pbook: Paralela, 2013. Disponível em: https://drive.google.com/drive/folders/OB4cIMwhxlufXaWIOQkVFZ2FaVEU Acesso em: 10 mai 2019

KNAPP, P. Princípios fundamentais da terapia cognitiva. IN (org). Terapia cognitivo-comportamental na prática psiquiátrica. Porto Alegre: Artmed, 2004. (pp 1941).

MUNDIM, Cleusa Pereira de O. O Papel da comunicação disfuncional no relacionamento de casal. Goiânia: Pontifícia Universidade Católica de Goiás, 2010. Disponível em <https://docplayer.com.br/19265878-O-papel-da-comunicacaodisfuncional-no-relacionamento-de-casal-cleusa-pereira-de-oliveira-mundim.html> Acesso em: 10 mai 2019

OSORIO, Luiz Carlos. Valle. VALLE, Maria Elizabeth Pascual. Manual de Terapia Familiar. Porto Alegre: Artmed, 2009

OTERO, V. R. L. \& GUERRELHAS, F. Saber falar e saber ouvir: a comunicação entre casais. IN: CONTE, F. C. \& BRANDÃO, M. Z. S. (Orgs.), Falo ou não falo? (pp. 7184). Arapongas: Mecenas, 2003.

PEÇANHA, Raphael Fischer; RANGÉ, Bernard Pimentel. Terapia cognitivocomportamental com casais: uma revisão. Rio de Janeiro: Revista Brasileira De Terapias Cognitivas, 2008. Vol 4, ํo 1 . Disponível em $<$ http://pepsic.bvsalud.org/scielo.php?script=sci_arttext\&pid=S1808-

$56872008000100009>$ Acesso em: 05 jun 2019

PEÇANHA, Raphael Fischer. Desenvolvimento de um protocolo piloto de tratamento cognitivo-comportamental para casais. Rio de Janeiro: UFRJ/IP, 2005. Disponível em: $<$ http://www.dominiopublico.gov.br/pesquisa/DetalheObraForm.do?select_action=\&c o_obra=42986> Acesso em 08 jun 2019. 
PORTELLA, Mônica. Estratégias de treinamento em habilidades sociais. Rio de Janeiro: Centro de Psicologia Aplicada e Formação, 2011. Disponível em: https://www.academia.edu/37553179/ESTRAT\%C3\%89GIAS_DE_TREINAMENTO_ EM_HABILIDADES_SOCIAIS Acesso em: 08 jun 2019

RANGÉ, B. (org.). Psicoterapias Cognitivo-comportamentais: Um diálogo com a psiquiatria. Porto Alegre: Artmed, 2008.

RANGÉ, B.; DATTILIO, F. M. In: RANGÉ, B. P. Psicoterapia comportamental e cognitiva: pesquisa, prática, aplicações e problemas. Campinas: L. Pleno, 2001, cap.15, 171-191.

RICHARDSON, Roberto Jarry. Pesquisa Social. Métodos e Técnicas. São Paulo: Atlas, 1999.

ROSSET, Solange Maria. Brigas na família e no casal: aprendendo a brigar de forma elegante e construtiva. Belo Horizonte: Artesã, 2016.

ROSSET, Solange Maria. O casal nosso de cada dia. São Paulo: Sol, 2014. Disponível em <https://docero.com.br/doc/n51nvs> Acesso em: 28 mai 2019

SARDINHA, Aline; FALCONE, Eliane Mary de Oliveira; FERREIRA, Maria Cristina. As relações entre a satisfação conjugal e as habilidades sociais percebidas no cônjuge. Psicologia Teoria e Pesquisa, Jul-Set 2009, Vol. 25 ํo 3. Disponível em <http://www.scielo.br/pdf/ptp/v25n3/a13v25n3.pdf>. Acesso em: 06 jun 2019.

SILVA, Lucilene Prado e; VANDENBERGHE, Luc. A importância do treino de comunicação na terapia comportamental de casal. Psicol. estud., Maringá, v. 13, n. 1, p. 161-168, Mar. 2008 . Disponível em $<$ http://www.scielo.br/scielo.php?script=sci_arttext\&pid=S141373722008000100019\&Ing=en\&nrm=iso >. Acesso em: 25 mai 2019 https://doi.org/10.1590/S1413-73722008000100019. 
SILVA, L. M. G. da; BRASIL, V. V.; GUIMARÃES, H. C. Q. C. P; SAVONITTI, B. H. R. A.; SILVA, M. J. P. da. Comunicação não-verbal: reflexões acerca da linguagem corporal. Ribeirão Preto: Revista Latino-am-enfermagem, 2000. vol 8, n,4. Disponível em <http://www.scielo.br/pdf/rlae/v8n4/12384> Acesso em: 10 mai 2019

VANDENBERGHE, Luc. Terapia comportamental de casal: uma retrospectiva da literatura internacional. Rev. bras. ter. comport. cogn., São Paulo , v. 8, n. 2, p. 145 160, dez. 2006.

Disponível

em

<http://pepsic.bvsalud.org/scielo.php?script=sci_arttext\&pid=S1517-

$55452006000200004 \&$ lng $=$ pt\&nrm=iso $>$.

VILLA, Miriam Bratfish; DEL PRETTE, Zilda A. P. Inventário de habilidades sociais conjugais. São Paulo: Casa do Psicólogo, 2012.

WRIGHT, Jesse H.; BASCO, Monica R.; THASE, Michael E. Aprendendo a terapia cognitivo comportamental. Porto Alegre: Artmed, 2008.

Enviado: Setembro, 2020.

Aprovado: Outubro, 2020. 